\title{
An innovative grape juice enriched in polyphenols by microwave-assisted extraction
}

\author{
Sheiraz Al Bittar, Sandrine Périno-Issartier*, Olivier Dangles, Farid Chemat \\ Université d'Avignon et des Pays de Vaucluse, INRA, UMR408, 84000 Avignon, France
}

\begin{abstract}
A B S T R A C T
The grape juice by-product obtained from grape traditional press was extracted by Microwave Hydrodiffusion and Gravity (MHG); a green extraction technique preliminarily optimized at $1 \mathrm{~W} / \mathrm{g}$. The MHG extract (MHGE) was analyzed by HPLC for identification and quantification of anthocyanins and other phenolic compounds. Then, MHGE was added to the natural juice (NJ) to produce an innovative grape juice (IJ). These three juices were evaluated for their total polyphenol content (TPC), total anthocyanin content (TAC) in addition to their sensorial characteristics. MHGE showed the highest values of TPC $(21.41 \pm 0.04 \mathrm{mg} \mathrm{GAE} / \mathrm{g}$ DW), TAC $(4.49 \pm 0.01 \mu \mathrm{g}$ MVGE/g DW). Moreover, IJ (grape juice enriched with MHGE) was richer in TPC $(6.70 \pm 0.01 \mathrm{mg}$ GAE/g DW) and TAC $(3.96 \pm 0.01 \mu \mathrm{g}$ MVGE/g DW) than NJ $(2.90 \pm 0.02 \mathrm{mg} \mathrm{GAE} / \mathrm{g}$ DW and $3.63 \pm 0.06 \mu \mathrm{g}$ MVGE/g DW, respectively).
\end{abstract}

Enriched juice

By-product

Microwave hydro-diffusion and gravity

Total phenol content

Anthocyanins

\section{Introduction}

Foods and beverages rich in polyphenols are potentially beneficial to human health due to the combination of in vitro antioxidant and cell-signalling effects expressed by these plant products (Hogan, Zhang, Li, Zoecklein, \& Zhou, 2009; Luque-Rodríguez, Luque de Castro, \& Pérez-Juan, 2007). As such, polyphenols could take part in the prevention of degenerative diseases, especially cardiovascular disease, brought about by diets rich in plant products (Anastasiadi, Pratsinis, Kletsas, Skaltsounis, \& Haroutounian, 2010; Mulero, Pardo, \& Zafrilla, 2010). Recently, many researches were aimed at developing natural polyphenols in the food industry instead of synthetic antioxidants, such as butylated hydroxytoluene (BHT) and butylated hydroxyanisole (BHA), which are suspected of carcinogenic potential (Spigno \& Faveri, 2007). On the other hand, anthocyanins are natural plant pigments (expressing a diversity of bright colours from red to blue) and potent watersoluble antioxidants. Hence, anthocyanins could be also used as natural pigments in the food, cosmetic and pharmaceutical industries (Torskangerpoll \& Andersen, 2005).

Grape is one of the fruits with the highest phenolic content. In fact, polyphenols are the most important constituents of grape juice after water (81-86\%), sugars (glucose, fructose) and organic (tartaric, malic and citric) acids. However, most of these valuable

\footnotetext{
* Corresponding author. Tel.: +33 0490144426; fax: +33 0490144441.

E-mail address: sandrine.issartier@univ-avignon.fr (S. Périno-Issartier).
}

phenolic compounds remain in by-products after juice processing in agreement with the phenolic distribution in grape as 30\% in skin, $60 \%$ in seeds and only $10 \%$ in pulp (Muñoz, Mestres, Busto, \& Guasch, 2008). Consequently, grape juice by-products are rich sources of anthocyanins and other phenolic compounds and have been the material of many extraction works using different grape parts, solvents, and methods (Table 1 ).

Moreover, it is well known that the phenolic content of grape juices is tightly related to their sensorial qualities in terms of colour and astringency (Gurak, Cabral, Rocha-Leao, Matta, \& Freitas, 2010). For instance, the specific sensorial characteristics of red wine are achieved after a maceration step that drastically increases its phenolic content (Revilla \& Ryan, 2000). On the other hand, many attempts were carried out to produce a grape juice richer in polyphenols (patent WO/2002/085137; ES 2177465). For example, a postharvest UV-C treatment of grape berries was combined with a maceration step to obtain high resveratrol contents without altering the sensorial properties of juice (Gonzàlez-Barrio, VidalGuevara, Tomas-Barberan, \& Espin, 2009).

In this article, fresh grape berries were pressed and the juice byproduct thus obtained was extracted by the MHG technique without solvent. The corresponding extract (MHGE) was analyzed by HPLC for its phenolic content. Then, MHGE was added to the total volume of natural juice ( $\mathrm{NJ}$ ) to produce an innovative juice (IJ) enriched in polyphenols in agreement with the European legislation (EC No. 258/97). The total polyphenol and anthocyanin contents of MHGE, NJ and IJ were compared as well as their sensorial characteristics. 
Version définitive du manuscrit publiée dans / Final version of the manuscript published in :

Food Chemistry (2013), Vol. 141, p. 3268-3272, DOI: 10.1016/j.foodchem.2013.05.134

Journal homepage: www.elsevier.com/locate/foodchem

Table 1

Reported techniques for the extraction of polyphenols and anthocyanins from grape and grape by-products.

\begin{tabular}{|c|c|c|c|c|}
\hline Samples & Solvent & Analytes & Methods & References \\
\hline Grape berries & $\begin{array}{l}\text { EtOH, MeOH } \\
\text { Synthetic wine } \\
\mathrm{MeOH}+\mathrm{HCl}\end{array}$ & $\begin{array}{l}\mathrm{Pp}^{\mathrm{a}} \\
\mathrm{Pp}^{\mathrm{a}} \\
\mathrm{An}^{\mathrm{a}}\end{array}$ & $\begin{array}{l}\mathrm{UAE}^{\mathrm{a}} \\
\text { Maceration } \\
\mathrm{SLE}^{\mathrm{a}}\end{array}$ & $\begin{array}{l}\text { Anastasiadi et al. (2010) } \\
\text { Muñoz et al. (2008) } \\
\text { Abert Vian et al. (2006) }\end{array}$ \\
\hline Grape skin & EtOH & $\mathrm{Pp}^{\mathrm{a}}$ and $\mathrm{An}^{\mathrm{a}}$ & SLE & Luque-Rodríguez et al. (2007) \\
\hline Skin, seeds & $\mathrm{MeOH}+\mathrm{EtOH}$ & $\mathrm{Pp}^{\mathrm{a}}$ & SLE, UAE, MAE ${ }^{\mathrm{a}}$, HPTE ${ }^{\mathrm{a}}$ & Casazza et al. (2010) \\
\hline Grape seeds & $\begin{array}{l}\mathrm{MeOH}+\mathrm{EtOH} \\
\mathrm{SC}-\mathrm{CO}_{2}\end{array}$ & $\begin{array}{l}\mathrm{Pp}^{\mathrm{a}} \text { and } \mathrm{An}^{\mathrm{a}} \\
\text { Seed oil }\end{array}$ & $\begin{array}{l}\text { SLE } \\
\text { SFE }\end{array}$ & $\begin{array}{l}\text { Orak (2007) and Bozan et al. (2008) } \\
\text { Passos et al. (2010) }\end{array}$ \\
\hline Marc & $\begin{array}{l}\mathrm{EtOH}+\mathrm{H}_{2} \mathrm{O} \\
\mathrm{EtOH}, \mathrm{Ac}_{2} \mathrm{O} \\
\mathrm{Ac}_{2} \mathrm{O}, \mathrm{SC}-\mathrm{CO}_{2} \\
\text { EtOH }+\mathrm{HCl}\end{array}$ & $\begin{array}{l}\mathrm{Pp}^{\mathrm{a}} \\
\text { Antioxidants } \\
\text { Antioxidants } \\
\mathrm{Pp}^{\mathrm{a}}\end{array}$ & $\begin{array}{l}\mathrm{UAE}^{\mathrm{a}} \\
\text { Maceration } \\
\mathrm{SFE}^{\mathrm{a}} \mathrm{CO}_{2} \\
\mathrm{MAE}^{\mathrm{a}}\end{array}$ & $\begin{array}{l}\text { Evren Oscan (2006) } \\
\text { Spigno and Faveri (2007) } \\
\text { Louli et al. (2004) } \\
\text { Pérez-Serradilla and Castro (2011) }\end{array}$ \\
\hline White wine marc & $\begin{array}{l}\mathrm{EtOH}+\left(\mathrm{HCl}, \mathrm{C}_{4} \mathrm{H}_{6} \mathrm{O}_{6}\right) \\
\mathrm{H}_{2} \mathrm{O}\end{array}$ & $\begin{array}{l}\mathrm{Pp}^{\mathrm{a}} \\
\mathrm{Pp}^{\mathrm{a}}\end{array}$ & $\begin{array}{l}\text { Maceration } \\
\text { HVED }^{\mathrm{a}}+\mathrm{SLE}\end{array}$ & $\begin{array}{l}\text { Makris et al. (2007) } \\
\text { Boussetta et al. (2009) }\end{array}$ \\
\hline
\end{tabular}

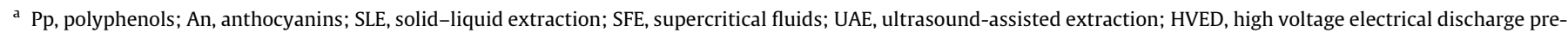
treatment; MAE, microwave-assisted extraction; HPTE, high pressure temperature extraction; synthetic wine: hydro alcoholic solution of tartaric acid (pH 3.2).

\section{Materials and methods}

\subsection{Material and juice preparing}

Two kilograms of red grape (Alphonse Lavallée, Vitis vinifera, South Africa) (including berries and stems) was pressed in a vertical laboratory hydraulic press (REUS, $P=200$ bars, Contes, France). Four hundred grams of press cake was collected and put directly in the microwave reactor to extract a red microwave juice (Fig. 1). IJ was prepared by mixing $\mathrm{Nj}(86 \%)$ with MHGE (14\%) which corresponds with the proportion of extracted juices (Table 3). Samples of three juices were freeze-dried before analyze.

\subsection{Chemicals}

All solvents used for chromatographic purposes were HPLC grade. HPLC water, acetonitrile and formic acid were from VWR (Fontenay-sous-Bois, France). The HPLC grade anthocyanin standard malvidin-3-O-glucoside was purchased from Extrasynthese (Lyon, France), while phenolic standards gallic acid, caffeic acid were from Alfa Aesar (Schitigheim, France). Catechin was purchased from Sigma-Aldrich (Saint Quentin Fallavier, France).

\subsection{Moisture content determination}

Moisture content in grape berries and grape by-product, before and after MHG extraction, was assessed by conventional DeanStark distillation according to the American Oil Chemist' Society (AOCS) official methods (Zill-e-Huma, Abert-Vian, \& Maingonnat, 2009). A moisture content of $80.9 \%$ was determined in the grape fresh berries, vs. $43.8 \%$ and $37.0 \%$ in the grape by-product before and after extraction, respectively.

\subsection{Solvent-free microwave hydrodiffusion and gravity}

Microwave hydrodiffusion and gravity was performed in a Milestone EOS-G microwave laboratory oven (Sorisole Bergamo, Italy) consisting in a multimode microwave reactor operating with a frequency of $2.45 \mathrm{GHz}$ and variable power ( $10 \mathrm{~W}$ increments, maximal value: $900 \mathrm{~W}$ ). The extraction vessels are made of Pyrex and have a capacity of $1 \mathrm{~L}$. During extraction, temperature was continuously monitored and recorded by sensors made of optic fibres inserted both in the plant material and in the reactor. The press cake was heated for $20 \mathrm{~min}$ at atmospheric pressure and at a constant power density of $1 \mathrm{~W} / \mathrm{g}$ without addition of solvent. The direct interaction of microwaves with plant water triggers the release of plant cell contents and the corresponding extract moves downwards under the effect of earth gravity through a spiral condenser outside the microwave cavity. The extraction was continued until no more extract was collected or overheating was detected.

\subsection{HPLC analysis}

HPLC analyses were performed using a Waters HPLC system (Guyancourt, Versailles, France) consisting of a Waters 600E pump, a Waters 717+ auto sampler, a Waters 2996 photodiode-array detector. The HPLC pumps, automatic sample, column temperature and diode-array system were monitored and controlled by the Waters Empower 2 Chromatography Data software program. The chromatographic separation was carried out on a Purospher Star RP-18 end-capped column $(250 \times 4 \mathrm{~mm}$ I.D.; 5 - $\mu \mathrm{m}$ particle size from Merck), with a RP18 guard column ( $4 \times 4 \mathrm{~mm}$ I.D.; $5-\mu \mathrm{m}$ particle size also from Merck). The injection volume was $20 \mu \mathrm{L}$. All analyses were repeated at least three times, only mean values were reported.

The wavelength for grape anthocyanin analysis was $530 \mathrm{~nm}$. The end-capped column and guard column were held at $25^{\circ} \mathrm{C}$ and the flow rate was set at $1 \mathrm{ml} / \mathrm{min}$. The mobile phase consisted of (A) formic acid/water/acetonitrile (10/60/30) and (B) water/formic acid (90/10).The solvent gradient used was: 0-40 min, (A) 20\% and (B) $80 \%$; 40-50 min, (A) 76\% and (B) 24\%; 50-53 min, (A) $90 \%$ and (B) 10\%; 53-60 min, (A) 20\% and (B) 80\%; 60-65 min, (A) 20\% and (B) $80 \%$. Identification of anthocyanins was carried out by comparing their elution order and UV-visible spectra. Quantification was carried out by using malvidin-3-O-glucoside (MVG) as an external standard in known concentration. A linear regression of the peak area vs. concentration $(0.05-0.35 \mathrm{mg} / \mathrm{ml})$ was used to quantify the compounds in the sample. Anthocyanin concentrations were calculated in $\mathrm{mg}$ of malvidin-3-O-glucoside equivalent (MVGE)/g of extract dry weight (DW).

The wavelength for total grape phenol analysis was $280 \mathrm{~nm}$. The end-capped column and guard column were held at $27^{\circ} \mathrm{C}$ and the flow rate was set at $1 \mathrm{ml} / \mathrm{min}$. The mobile phase consisted of (A) water/formic acid (94/6) and (B) water/acetonitrile/formic acid (65/30/5). The solvent gradient used was: 0-10 min, (A) 99\% and (B) $1 \%$; 10-45 min, (A) 70\% and (B) 30\%; 45-75 min, (A) 20\% and (B) $80 \%$; 75-80 min, (B) $100 \%$; $80-85 \mathrm{~min}$, (A) $99 \%$ and (B) $1 \%$; 85-90 min, (A) $99 \%$ and (B) $1 \%$. Identification of phenolic compounds was carried out by comparing the elution order and 
UV-visible spectra. External standards (caffeic acid, gallic acid, catechin) of known concentration $(0.1-1 \mathrm{mg} / \mathrm{ml})$ were used for calibration through linear regressions. Final concentrations were expressed in $\mathrm{mg} / \mathrm{g}$ DW.

\subsection{Determination of total phenolic contents (TPC)}

TPC was estimated by the Folin-Ciocalteu method (Zill-e-Huma et al., 2009) using a kit (SEPPAL (Isitec-lab), France) especially suitable for food products. This kit includes: Reagent A (modified Folin-Ciocalteu reagent), reagent $B$ (alkaline buffer) and a gallic acid solution $(3 \mathrm{~g} / \mathrm{L})$. A small volume $(20 \mu \mathrm{L})$ of $\mathrm{H}_{2} \mathrm{O}$ (blank), gallic acid solution (standard) or the extract (sample) was mixed with $(2 \mathrm{ml}$ ) of reagent A. After $1 \mathrm{~min}, 1 \mathrm{ml}$ of reagent B was added. The mixtures were allowed to stand for 30 min in the dark at room temperature. Then, their absorbance was measured at $760 \mathrm{~nm}$ with a diode-array Hewlett-Packard 8453 spectrophotometer. TPC were calculated by using the following formula:

$\mathrm{TPC}=3 \times\left(A_{\mathrm{s}}-A_{0}\right) /\left(A_{\mathrm{st}}-A_{0}\right)$

where $A_{\mathrm{s}}$ was the sample absorbance, $A_{0}$ the blank absorbance and $A_{\mathrm{st}}$ the standard absorbance. Results were expressed as mg gallic acid equivalent (GAE)/g DW.

\subsection{Determination of total anthocyanin contents (TAC)}

TAC of extracts was determined by measuring the visible absorbance at $530 \mathrm{~nm}$ against a blank of $10 \%$ formic acid in distilled water. A calibration curve was built with MVG solutions (25, $12.5,6.25,3.125 \mu \mathrm{g} / \mathrm{ml}$ in $10 \%$ aqueous formic acid). All samples were diluted in $10 \%$ aqueous formic acid until the absorbance was within the calibration limits. The results are expressed in $\mathrm{mg}$ MVGE/g DW.

\subsection{Colour measurements}

The colour of juices was measured by using the CIE $L^{*} a^{*} b^{*}$ system (CIE 1986) and a Minolta CR 400/410 colorimeter equipped with a pulsed Xe lamp. The $\left(L^{*}, a^{*}, b^{*}\right)$ space models the human eye perception in terms of luminance and chrominance. $L^{*}$ expresses the luminance and changes from 0 for black to 100 for white, $a^{*}$ and $b^{*}$ represent the green-red axis and blue-yellow axis respectively and vary from -60 to +60 . Any colour can be expressed in the $L^{*}, a^{*}, b^{*}$ rectangular coordinate system. Hue angle $h_{\mathrm{ab}}$ is defined as: $h_{\mathrm{ab}}=\arctan \left(b^{*} / a^{*}\right)$. Remarkable $h_{\mathrm{ab}}$ values are: $0^{\circ}$ (red), $270^{\circ}$ (or $-90^{\circ}$, blue), $90^{\circ}$ (yellow), $45^{\circ}$ (orange) and $180^{\circ}$ (green). Colour assessment of the samples was carried out after colorimeter calibration with a white plaque. The fresh samples (before freeze-drying) were placed in a special quartz cell for measurements in triplicate. Mean values were reported.

\subsection{Sensorial analysis}

The sensory analyses of the three fresh juices (MHGE, NJ, IJ) were conducted by a panel consisting of 15 graduate students from Avignon University, France. The subjects were seated in sensory booths with appropriate ventilation and lighting. The samples were presented to each panellist in polystyrene cups. For the three juices, the following attributes were evaluated: colour, smell, acidity, astringency and global acceptance. For overall quality, the scale ranged from 0 (weakest attribute) to 10 (strongest attribute) and a score of 5 corresponded to an ideal perception. The panellists gave their preferences for each sample on a hedonic scale (0-10). The average of the points was calculated for each attribute.

\section{Results and discussion}

\subsection{Proposed MHG mechanism}

In MHG extraction, the two transport phenomena, heat and mass transfer, are in the same direction from the inside of the extracted material to the bulk reactor (Abert-Vian, Tomao, Coulomb, Lacombe, \& Dangles, 2006). Consequently, the microwave-assisted extraction process can be carried out without solvent. In this case, heat is dissipated volumetrically within the irradiated medium, and heat transfer occurs from the sample to the colder environment. By contrast, in conventional solvent extraction, heat is transferred from the heating medium to the interior of the sample and mass transfer occurs from the inside to the outside. In conventional heating, heat transfer depends on thermal conductivity, on the temperature gradient across the sample, on convection currents in fluids. As a result, the temperature increase is often rather slow. By contrast, in microwave heating, due to the volumetric heating effect, much faster temperature increases can be obtained, depending on the microwave power and the dielectric loss factor of the material being irradiated. The juice situated inside the cells is extracted by hydrodiffusion (extraction and diffusion) which is intensified by microwave heating.

\subsection{Microwave heating and extraction kinetics}

This efficient microwave absorption results in a rapid increase in temperature leading to the rupture of cells by the in situ water, followed by the release of crude juice and steam. The heating phenomenon proceeding in the centre of the grape by-product was detected by a temperature sensor including optic fibres. Different phases in the temperature and mass variations were distinguished (Fig. 2). During the first phase (phase A, induction period), no

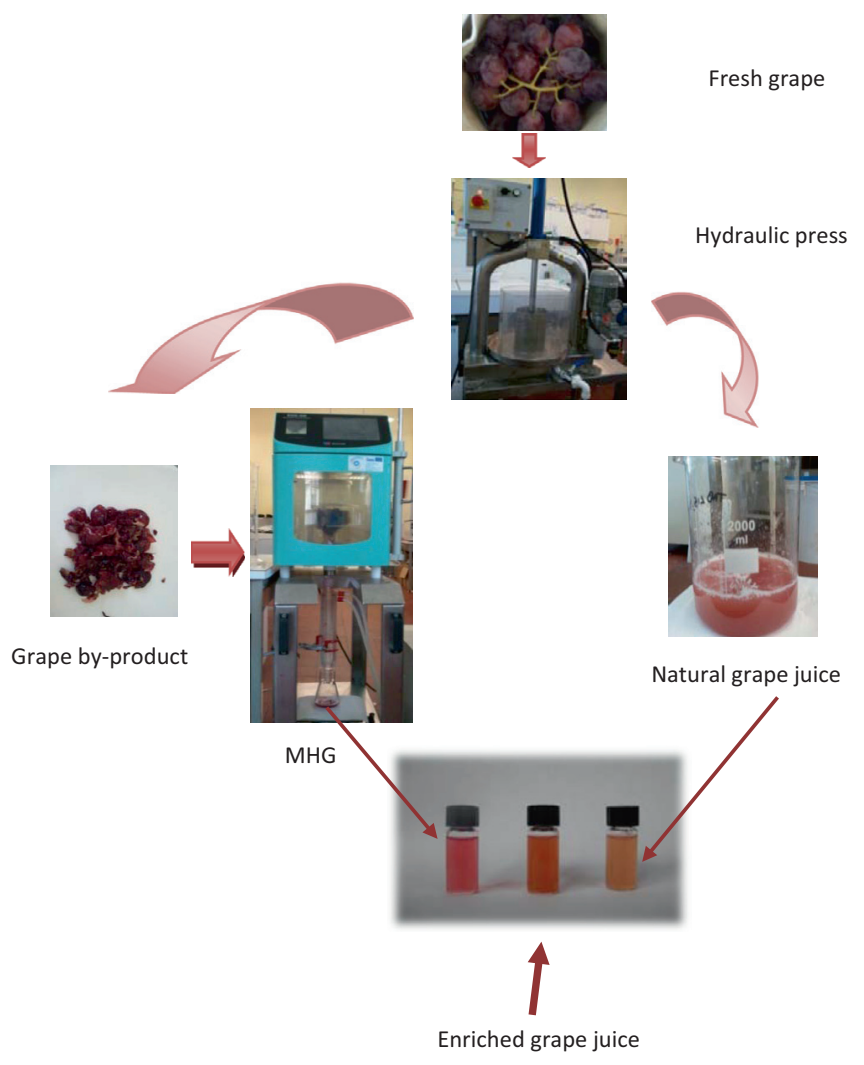

Fig. 1. The preparation process of polyphenol-supplemented grape juice. 
Version définitive du manuscrit publiée dans / Final version of the manuscript published in :

Food Chemistry (2013), Vol. 141, p. 3268-3272, DOI: 10.1016/j.foodchem.2013.05.134

Journal homepage: www.elsevier.com/locate/foodchem

Table 2

HPLC identification and quantification of anthocyanins and other phenols in MHGE.

\begin{tabular}{llll}
\hline Anthocyanins at $530 \mathrm{~nm}$ & Quantity $^{\mathrm{a}}$ & $\begin{array}{l}\text { Other phenols at } \\
280 \mathrm{~nm}\end{array}$ & Quantity $^{\mathrm{b}}$ \\
\hline Delphinidin-3-O-glucoside & 0.26 & Gallic acid & 0.16 \\
Cyanidin-3-O-glucoside & 0.06 & Catechin & 4.70 \\
Petunidin-3-O-glucoside & 0.31 & Caffeic acid & 1.96 \\
Peonidin-3-O-glucoside & 0.89 & & \\
Malvidin-3-O-glucoside & 2.15 & & \\
Malvidin-3-O-(6-O- & $\mathrm{ND}$ & & \\
$\quad$ acetyl)glucoside & & & \\
\hline
\end{tabular}

anthocyanin concentration expressed in mg MVGE/DW.

b Phenolic acid concentration expressed in $\mathrm{mg} / \mathrm{g}$ DW.

Table 3

Total comparison between MHGE, NJ and IJ in yield, Brix degree, $\mathrm{pH}$, colour, TPC and TAC.

\begin{tabular}{|c|c|c|c|c|c|c|c|}
\hline Sample & $\begin{array}{l}\text { Weight } \\
\text { (g) }\end{array}$ & $\begin{array}{l}\text { Volume } \\
(\mathrm{ml})\end{array}$ & $\begin{array}{l}\text { Brix } \\
\text { degree }\end{array}$ & $\mathrm{pH}$ & $\begin{array}{l}\text { Colour: } L^{*}, \\
h_{\mathrm{ab}}\end{array}$ & $\mathrm{TPC}^{\mathrm{a}}$ & $\mathrm{TAC}^{\mathrm{b}}$ \\
\hline MHGE & 185.31 & 184 & 5 & 4.03 & $\begin{array}{l}16.54, \\
11.86^{\circ}\end{array}$ & $21.41 \pm 0.01$ & $4.49 \pm 0.01$ \\
\hline $\mathrm{NJ}$ & 1397.9 & 1250 & 14 & 4.10 & $26.37,65.5^{\circ}$ & $2.90 \pm 0.02$ & $3.63 \pm 0.06$ \\
\hline IJ & 1583.21 & 1434 & 10 & 4.09 & $23.48,12.3^{\circ}$ & $6.7 \pm 0.002$ & $3.96 \pm 0.01$ \\
\hline
\end{tabular}

a TPC is expressed in $\mathrm{mg} \mathrm{GAE} / \mathrm{g}$ DW.

b $\mathrm{TAC}$ is expressed in mg MVGE/g DW.

increase in temperature was observed in the grape by-product (initial temperature $=0{ }^{\circ} \mathrm{C}$ ). Moreover, no mass loss in of plant material was observed. This phase ended with the appearance of the first drop of water outside the microwave cavity. During the next phase (phase B), the water inside the plant material was heated up, then diffused out of plant matrix and moved downward under the influence of earth gravity. At this point, the temperature reached a plateau at $100^{\circ} \mathrm{C}$ and remained constant until the complete extraction of unbound water. A sharp decline in mass of plant material was observed during this phase. At last, when there was only tightly bound water left, the temperature started to further increase, which led to the burning phase (phase C) and no further mass loss was observed.

\subsection{Identification and quantification of MHGE by HPLC}

HPLC analyses allowed the identification of seven different anthocyanins at $530 \mathrm{~nm}$ (Table 2). Whatever the microwave power used, the most abundant anthocyanin in the grape by-product extract was malvidin-3-O-glucoside in agreement with the literature (Abert-Vian et al., 2006). The other anthocyanins identified were peonidin-3-O-glucoside, petunidin-3-O-glucoside, delphinidin-3$O$-glucoside and malvidin-3-O-(6-O-p-coumaryl) glucoside. Cyanidin-3-O-glucoside and malvidin-3-O-(6-O-acetyl) glucoside were also detected in traces in MHGE. The total anthocyanin content estimated by HPLC was consistent with the value determined by UV-visible spectroscopy (Luque-Rodríguez et al., 2007). In addition to anthocyanins, gallic acid, caffeic acid and catechin were the main phenolic compounds identified and quantified in MHGE at $280 \mathrm{~nm}$ (see Table 2).

\subsection{Total juice evaluation}

The Folin-Ciocalteu method allowed a good discrimination between MHGE, NJ and IJ. MHGE showed a higher TPC $(21.41 \pm 0.04 \mathrm{mg}$ GAE $/ \mathrm{g}$ DW) than $\mathrm{NJ}(2.90 \pm 0.02 \mathrm{mg} / \mathrm{g} \mathrm{DW})$ and IJ $(6.40 \pm 0.01 \mathrm{mg} / \mathrm{g} \mathrm{DW})$. By contrast, no large differences in total

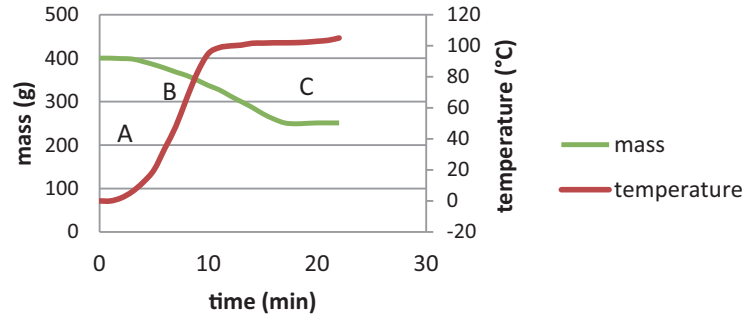

Fig. 2. Mass and temperature variations in MHG extraction at optimized power $(400 \mathrm{~W})$ : $\mathrm{A}=$ heating phase, $\mathrm{B}=$ extracting phase and $\mathrm{C}=$ burning phase.

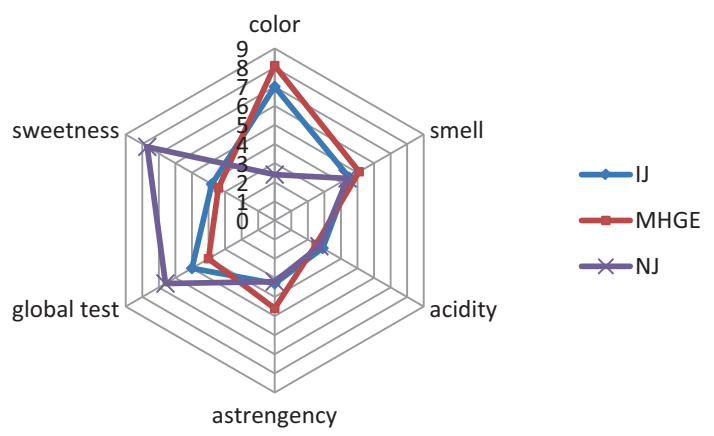

Fig. 3. Sensorial tests investigated in three jus MHGE, IN and NJ.

anthocyanin content were observed between the three juices (Table 3). In a previous works (Orak, 2007)], reported that the correlation between antioxidant activity and TPC was more significant than with TAC. Thus, a high antioxidant activity of MHGE is expected due to its high content in colourless polyphenols.

MHGE, NJ and IJ were also compared by their physical characteristics as weight, volume, Brix degree, $\mathrm{pH}$ and colour (Table 3). The three juices have close $\mathrm{pH}$ values but different sweetness values as expressed by Brix degrees. As evidenced by a $h_{\mathrm{ab}}$ value near $0^{\circ}$, the colour of the natural juice supplemented with the MHG extract was darker and redder than the natural juice $\left(h_{\mathrm{ab}} \approx 45^{\circ}\right)$.

\subsection{Sensorial tests}

The results of sensorial tests for the three juices (Fig. 3) are correlated with their physical characteristics. The panellists found $\mathrm{NJ}$ sweeter than the other juices, whereas the astringency, acidity, smell and global evaluation of the three juices approximately gave the same attributes. Otherwise, the colour of the supplemented juice (IJ) was more attractive than that of the natural juice, which is an important point as colour is typically the first sensorial quality that attracts attention and influences the consumer's choice.

\section{Conclusion and perspectives}

MHG is a green extraction method that offers important advantages like short extraction time (20 min), low energy input and no requirements in solvents. This study proved the efficiency of MHG in the extraction of polyphenols and anthocyanins from grape byproducts. Moreover, the juice supplemented in MHG extract had a more attractive colour and a higher polyphenol content while retaining acceptable organoleptic characteristics. Thus, MHG comes up as a sustainable food process that offers opportunities to meet the growing demands for healthier food products. 
Version définitive du manuscrit publiée dans / Final version of the manuscript published in :

Food Chemistry (2013), Vol. 141, p. 3268-3272, DOI: 10.1016/j.foodchem.2013.05.134

Journal homepage: www.elsevier.com/locate/foodchem

\section{Acknowledgements}

This scientific study was carried out as part of the Alcotra EcoExtraction Transfrontalière project framework which brings together private and public-sector stakeholders (University of Avignon, European University of Fragrances \& Flavours, FranceAgriMer, University of Turin and Technogranda). We would also like to warmly thank our co-funding partners, i.e. the European Union (FEDER), the French and Italian governments, the Piedmont region as well as ADEME and the Conseil Régional ProvenceAlpes-Côtes d'Azur through the Etat-Region-ADEME framework programme. Their financial support has helped partners successfully achieve the project's scientific objectives.

\section{References}

Abert-Vian, M., Tomao, V., Coulomb, P. O., Lacombe, J. M., \& Dangles, O. (2006). Comparison of the Anthocyanin composition during ripening of Syrah grapes grown using organic or conventional agricultural practices. Journal of Agricultural and Food Chemistry, 54, 5230-5235.

Anastasiadi, M., Pratsinis, H., Kletsas, D., Skaltsounis, A.-L., \& Haroutounian, S. A . Food Research International, 43, 805-813.

Boussetta, N., Lanoisellé, J.-L., Bedel-Cloutour, C., \& Vorobiev, E. (2009). Extraction of soluble matter from grape pomace by high voltage electrical discharges for polyphenol recovery: Effect of sulphur dioxide and thermal treatments. Journal of Food Engineering, 95, 192-198.

Bozan, B., Tosun, G., \& Özcan, D. (2008). Study of polyphenol content in the seeds of red grape (Vitis vinifera L.) varieties cultivated in Turkey and their antiradical activity. Food Chemistry, 109, 426-430.

Casazza, A. A., Aliakbarian, B., Mantegna, S., Cravotto, G., \& Perego, P. (2010). Extraction of phenolics from Vitis vinifera wastes using non-conventional techniques. Journal of Food Engineering, 100, 50-55.
Gonzàlez-Barrio, R., Vidal-Guevara, M. L., Tomas-Barberan, F. A., \& Espin, J. C. (2009). Innovative Food Science \& Emerging Technologies, 10, 374-382.

Gurak, P. D., Cabral, L. M. C., Rocha-Leao, M. H. M., Matta, V. M., \& Freitas, S. P. . Journal of Food Engineering, 96, 421-426.

Hogan, S., Zhang, L., Li, J., Zoecklein, B., \& Zhou, K. (2009). LWT - Food Science and Technology, 42, 1269-1274.

Louli, V., Ragoussis, N., \& Magoulas, K. (2004). Recovery of phenolic antioxidants from wine industry by-products. Bioresource Technology, 92, 201-208.

Luque-Rodríguez, J. M., Luque de Castro, M. D., \& Pérez-Juan, P. (2007). Bioresource Technology, 98, 2705-2713.

Makris, D. P., Boskou, G., \& Andrikopoulos, N. K. (2007). Recovery of antioxidant phenolics from white vinification solid by-products employing water/ethanol mixtures. Bioresource Technology, 98, 2963-2967.

Mulero, J., Pardo, F., \& Zafrilla, P. (2010). Journal of Food Composition and Analysis, 23, 569-574.

Muñoz, S., Mestres, M., Busto, O., \& Guasch, J. (2008). Analytica Chimica Acta, 628, 104-110.

Orak, H. H. (2007). Scientia Horticulturae, 111, 235-241.

Oscan, E. (2006). Ultra sound assisted extraction of phenolics from grapes pomace, The graduate school of natural and applied sciences, Middle east technical university.

Passos, C. P., Silva, R. M., Silva, F. A. D., Coimbra, M. A., \& Silva, C. M. (2010) Supercritical fluid extraction of grape seed (Vitis vinifera L.) oil. Effect of the operating conditions upon oil composition and antioxidant capacity. Chemical Engineering Journal, 160, 634-640.

Pérez-Serradilla, J. A \& de Castro, M. D. L (2010). Microwave-assisted extraction of phenolic compounds from wine lees and spray-drying of the extract. Food Chemistry, 124, 1652-1659.

Revilla, E., \& Ryan, J. M. (2000). Journal of Chromatography A, 881, 461-469.

Spigno, G., \& Faveri, D. M. D. (2007). Journal of Food Engineering, 78, 793-801.

Torskangerpoll, K., \& Andersen, M. (2005). Food Chemistry, 89, 427-440.

Zill-e-Huma, M., Abert-Vian, J. F., \& Maingonnat, F. (2009). Chemat. Journal of Chromatography A, 1216, 7700-7707. 